\title{
Evaluation of Dental Procedures on Hemophilic Patients in a Comprehensive Program for the Care of Hemophilia
}

(Part 3)

\author{
by \\ Osamu CHIONO*
}

\section{Discussion}

There are three major problems in the treatment of hemophiliacs of which little has been published in the dental literature. One of these is soft tissue intraoral bleeding, which can be a major problem and require many days of hospitalization. Bleeding from the tongue is very difficult to control in a normal patient, and in a hemophiliac it can be a serious problem. Andonian, Dietrich, and Whiteman [3] reported that hemorrhages in the lax tissues beneath the tongue dissecting into the anterior nuchal muscles or posteriorly to the pharynx are potentially dangerous, as airway embarrassment may occur. They stress that one of the early signs of impending neck bleeding is a hematoma under the tongue. Control of bleeding from the lips and other soft oral tissues was also found to be difficult. Injury to the tongue and the other soft tissues during operative procedures is best eliminated by the use of the rubber dam. In the mandibular arch, a rubber dam should always be used, if for no other reason than to protect the patient's tongue. In sum, dentists should protect the patient as much as possible at all times during operative procedures.

The presence of periocoronal tissue over erupting teeth may be a source of hemorrhage and pain, especially during the eruption of lower first permanent molars. The decision as to whether this tissue should be surgically removed or to wait for normal tissue recession often depends on the patient's past medical and dental history. One method of solving this problem is to fabricate a rubber mouth guard, which places the upper tooth out of occlusion, so that the tissue will not be further traumatized during its normal recession.

The second problem is traumatic injury to the hard and soft oral tissues. When this occurs the patient should be referred immediately to the hospital for plasma therapy. Assessment of the dental injury should be made later. In one case where this occurred, the patient's hospitalization period was 10 days and was further complicated

* Former associate clinical professor at the University of Southern California, Los Angeles. Currently, Chief of dental service, California Hospital Pediatric Center.

This concludes the comprehensive study on hemophilia, which appeared in the Journal in three installments because of size (Editor). 
by an ontoward reaction to plasma. When a tooth has been fractured, local anesthetic and the necessary emergency treatment can then be given. In instances where a tooth has been fractured without soft tissue injury or pulpal involvement, treatment may be performed without local anesthetic. Because of the previous experience with painful hemarthrosis, many hemophiliacs have a high tolerance to dental pain. As this study progressed, fewer patients received local anethesia for restorative dentistry.

In a personal communication, S. L. Dietrich, M.D., Medical Director of the Hemophilia Project, summarizes medical aspects of dental care as follows:

"A description of medical complications entailed by hemophilia underscores the principle that dentistry must not be begun, must not even be undertaken, except in consultation with the physician who is acquainted with the patient's individual condition. The medical complications of hemophilia are of three kinds, and two of the three are continuously present as potential problems during dental care.

"Hemophilic complications are: 1) those directly resulting from bleeding, 2) those residual to hemorrhages especially in joints and closed soft tissue compartments, and 3) those secondary to therapy. Complications of the first type, which arise from bleeding, may occur in different sites, and the possible sites include mouth (e.g., the tissues beneath the tongue) and neck. In respect to complications of the third sort, which arise secondary to therapy, the most common of these is an allergic reaction to plasma or blood, which is generally controlled by the administration of antihistamine. On rare occasions a patient acquires a refractory state and worsens despite given blood or plasma; there is serum hepatitis (acquired from transfusion of infectious blood or plasma) to be guarded against. Thus when oral surgery does entail replacement therapy, the prescription of plasma and subsequent management of the replacement course must be the responsibility of the physician.

"Since dentists do not have and are not expected to have the medical knowledge to deal with these conditions, the availability of a physician with the appropriate speciality is an essential requirement before the dentist undertakes the case. 'Teamwork' for the patient's welfare between the physician and the dentist means specific consultation before and during the course of dental treatment. This teamwork implies the utilization of modern medical knowledge. It is one of the two factors that make feasible in the mid-twentieth century the dental treatment of the hemophilic patient- the other factor being the advances and refinements of modern dental science" [22].

In the past dental extractions were considered a dangerous elective procedure for the hemophiliac. The literature abounds with reports of the dangers, histories of prolonged hemorrhage, the use of many units of plasma, chemostatic agents, and local methods in order to create hemostasis. Several factors which may have caused these difficulties became evident as one reviews the cases. Among these are:

1) The lack of critical assessment of the medical and dental history

2) Insufficient preoperative administration of plasma

3) Too radical a form of surgery

4) Removal of too many teeth at one time

5) Failure to prepare adequate means of control of local hemorrhage

6) Premature dismissal of patient from the hospital 
7) Lack of consideration of the psychological problems of the patient.

Since it was our goal to perform dental extractions for the hemophiliac safely and in a manner that would minimize the amount of pain, hospitalization, and emotional stress, and would avoid bleeding complications, it was decided that no more than two multirooted teeth would be extracted at one time. The reasons follow:

1) The defective factor is thought to be more readily utilized with an increased number of wound sites.

2) The greater the number of adjacent teeth extracted, the greater is the risk of bleeding [6].

3) Fewer bleeding sites are more easily controlled by local means.

4) Less emotional stress is placed upon the patient.

5) The amount of plasma replacement is reduced due to the decrease of blood loss.

The primary reason for not using the acrylic splint or other local devices after extraction was that the investigators believe local means are not the best for controlling hemorrhage. We concur with McIntyre [62] that splints may produce hematomas. The investigations of Hayward,[37] Archer,[6] and Sherry[89] have shown that a splint also can cause impingement and maceration of gingival tissue. The psysiologically defective mechanism must be corrected and maintained during the healing process. The literature indicates that if the patient is maintained at approximately 20 to 30 per cent of his normal AHF level, this is sufficient to continue the healing process. It is thought that the amount of plasma to maintain this state is not constant and that the amount utilized may be related to the area and the number of wounds present. The greater the area, the sooner will the defective factor be utilized. If this is true, it will necessitate additional plasma to maintain the 20 to 30 per cent level. The biological half-life of infused AHF is eight to 11 hours; and after 22 hours it is only 20 per cent of the original AHF level. One must consider Abildgaard's[1] statement that an attempt to maintain AHF level may lead to congestive heart failure due to the overexpansion of the total blood volume. Kerr[46] has also stated that other complications which may arise are thrombophlebitis, generalized allergic reactions, proteinuria, and the formation of circulating inhibitors. It is also believed that when trauma has occurred, hematomas result. It is thought that the missing factor is utilized in the dissolution of these hematomas in addition to the healing of the wound site.

Another factor to recognize is that for some unknown reason the hemophiliac has spontaneous bleeding episodes. If teeth are extracted during this time, a greater amount of the missing factor may be necessary to maintain the physiological level required for normal coagulation. Active bleeding, circulating anticoagulants, fever, infections, and the recurrence of bleeding are thought to be factors which can reduce the longevity of the infused (AHF).

The emotional state of the patient may also determine the amount of plasma necessary to maintain the proper level. This may be caused either by a decrease in normal production of the AHG due to emotional stress or by increased use of the factor. Whatever the reasons, we agree with Lucas and others that the psychosomatic factors must be considered if good hemostasis is to be established and hospitalization 
time shortened.

Surgicel is a surgical packing of regenerated alpha cellulose which is readily absorbable. The material has an affinity for hemoglobin which results in the formation of a gel when in contact with blood[32]. This packing is most beneficial in the healing process. When saturated with thrombin powder, it helps to create a clot and maintains the thrombin in close contact with the injured capillary vessel. Thrombin in the coagulation cycle is formed from prothrombin which acts on fibrinogen to produce fibrin (see Chart 1). It is not normally present in the circulating blood. The investigators have found that one of the most effective means of controlling capillary bleeding at the surgical site is to keep the thrombin as close to the capillaries for as long a period as possible. Pressure dressings placed over the extraction site are most helpful in stopping bleeding and oozing. This pressure also prevents the gel and thrombin from being washed away from the injured terminals of the capillaries.

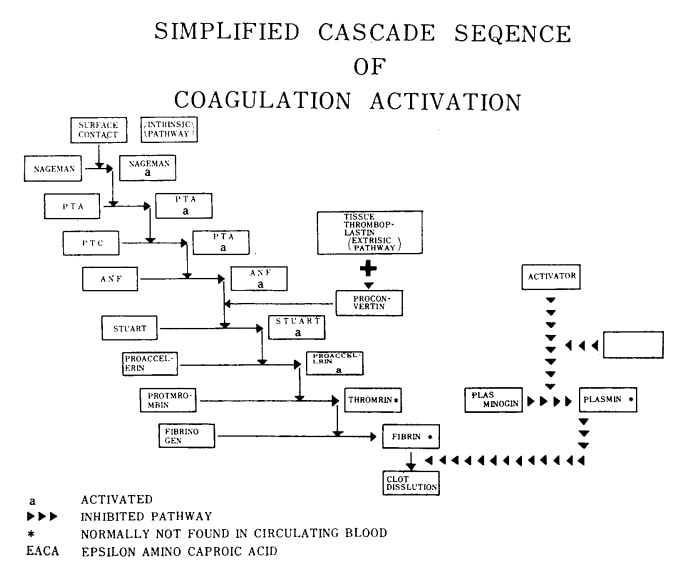

Quick[84] stated that nearly all bleeding in hemophiliacs comes from minute arterial vessels and from small cuts which involve only capillaries. These vessels and capillaries rarely bleed for any abnormal length of time. Injured capillaries apparently are closed by an inherent contracting force and by the natural adhesive properties of damaged endothelium, which is not impaired in hemophilia. Thus, any measure which succeeds in reducing the number of injured arterial vessels should result in reduction of postoperative bleeding.

Another effective way to control the capillary bleeding is to use an anesthetic with a vasoconstrictor. Injections into the periodontal ligament space are recommended for two reasons: First, it is a safer procedure than deep penetration injection, such as the mandibular block; and second, the number of wounds is reduced, as the injection will be at the site of the extraction wound. Some of our dental staff have employed this technique on nonhemophiliacs where bilateral mandibular extractions were required.

It must be remembered that local treatment methods are effective for only a few hours and that the healing of a dental extraction wound requires days. Continued 
replacement therapy of the missing factor is still the most ideal means of creating longterm hemostasis.

The reason the formocresol pulpotomy technique was used on primary teeth is that this technique has been shown to give the greatest percentage of clinical success. It also has been used by some clinicians on nonvital teeth.

In our private practice it was noted that in most instances, even if the pulpotomies were unsuccessful, the nonhemophilic patient usually does not have acute infection or pain, but rather, chronic inflammation, destruction of bone, and a fistula. Because of these observations, the investigators felt that this technique is warranted in treating hemophiliacs. The technique of indirect pulp capping is receiving wide acceptance in dentistry. This procedure is ideally suited for hemophiliacs, in that it can usually be performed without local anesthetic, and the pulp is not exposed. Should this procedure fail, the patient may have root canal therapy with plasma replacement therapy at a later date.

Dentists should be informed that there is no clinically observable morphological or anatomical difference in dentition between a hemophiliac and a "normal" patient. However, two factors must always be considered during dental procedures: a) Local anesthesia must be used judiciously; and b) Careful conservative methods are the best dental procedures.
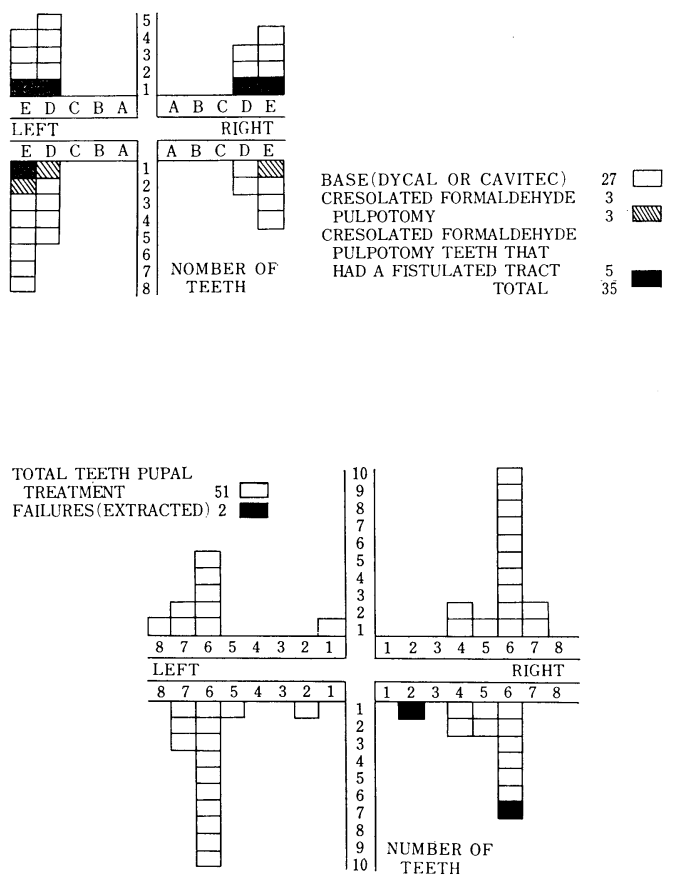

Restorative and preventive dentistry is the best service rendered the hemophiliac. Early dental treatment not only obviates the need for oral surgery but also manifests 
the importance of proper oral hygiene in the hemophiliac. From the numerous papers written regarding oral surgery, one assumes that a hemophiliac is always a dental cripple, and his ultimate fate is to become edentulous. This study has proved the feasibility of adequate operative care. Just as with any "normal" patient who has been made aware of the importance of dental hygiene and the results of negligence, a hemophiliac will take an added interest in his dentition and will work hard to prevent caries.

Every restoration placed for a hemophiliac eliminates a potential extraction. By patient education and early treatment of caries, theoretically, it is possible for a hemophiliac to have a full complement of teeth and a minimum of surgical procedures.

Prophylactic odontotomy should be practiced in hemophiliacs since recall visits may be erratic because of their many problems in daily living. The present author has found that this procedure minimizes apprehension, pain, abscesses, or extensive caries which are difficult to restore. The work for the dentist is also lessened, since a single procedure usually assures complete treatment for that tooth.

Early care of periodontal conditions is important. Complete etiologic correction is vital. Symptomatic treatment is not in itself satisfactory. Scaling, curettage, and root planing should be carefully performed if necessary.

Most current research has been focused on oral surgery, but attention is needed on other dental specialties. We need studied evaluations of the treatment of hemophiliacs in the fields of periodontics, endodontics, orthondontics, prosthodontics, pedodontics, as well as oral surgery. There is to date, for example, no published record of a hemophiliac undergoing orthodontic treatment. Many hemophiliac patients desire and require orthodontic work. However, due to the probably necessity of extractions, the uncertainty of this procedure, and the lack of knowledge in treating these patients, many hemophiliacs are not now receiving any orthodontic care. They are thereby denied the aesthetic, functional, and psychological well-being derived from orthodontic treatment. In addition to this, malposition of teeth may also lead eventually to periodontal problems and caries.

For another example, Bjordnal[10] furnishes one of the few papers published on endodontics, and none has been published on periodontics or periodontal surgery. Although a plethora of information on oral surgery for hemophiliacs is available in the literature, little research of great depth and valid scientific and statistical significance has been done. Due to the large number of hemophiliacs participating in our Hemophiliac Program, future studies of this group should continue to be statistically significant.

A rule has developed in the literature that extractions for hemophiliacs should be performed in the hospital. Our experience indicated that not all hemophiliacs require hospitalization. Hemophiliacs must be considered on an individual basis for treatment rather than as a group. But individualized treatment necessitates a thorough knowledge on the dentist's part of each hemophiliac he is to treat. It is our firm belief that in the future many hemophiliacs will not require hospitalization for oral surgery and that replacement therapy can be reduced in volume, thereby reducing the possible complications inherent in this procedure. The development of AHF concentrate may prove to be the key to the application of this concept. 
The relation of the psychological needs of hemophiliacs to dentistry has been neglected until recently. Lucas is the chief dental investigator in this area. Investigators should in the future study the hemophiliac's problems from a behavioral aspect. Such a program should include an evaluation of the usefulness of hypnosis in child menagement and its use as either a substitute or an adjunct to anesthesia, since block anesthesia may be contraindicated in some cases of hemophilia, i.e., refractory type hemophilia.

It must be emphasized that in the dental care of hemophiliacs perhaps more than in any other condition, team work is essential. It is not enough to know that a patient is a hemophiliac; it is important to know his type of hemophilia, the severity of his condition, and his previous responses to plasma therapy, since response may range from excellent to practically nil.

Some of the hemophiliacs treated neglected their oral care and came to the dental clinic only on an emergency basis. Dental education and reduction of fears should be an important aspect of their over-all dental care. The majority of patients treated were cooperative and became excellent dental patients. All of the above factors must be considered in an active total program of dental care for the hemophiliac.

\section{Summary and Conclusion}

Progress to date on this hemophilia research has been both definite and positive. In the dental treatment of hemophilic patients, emphasis has been given to the pedodontic aspect. It has been shown that with consultation of the patient's physician and using standard operative procedures with precautionary care, hemophiliacs can be treated, and dental health can be achieved in a hemophiliac. A comprehensive program will minimize the necessity for extractions, and the subsequent sequela of tooth migration, periodontal disease, extraction of other teeth, and prosthetic appliances. Conjoined with the medical approach, dental surgery can often avoid or minimize hospitalization.

Two fundamental statements summarize the treatment plan for hemophiliacs: a) For hemophiliacs, as for all, there is no substitute for good dental procedures, and dental treatment is not elective but mandatory; b) Current knowledge of procedures and techniques for the prevention and treatment of the hemophiliacs' dental ills no longer justifies the dentists' hesitation in treating them.

The hemophiliac has the usual dental problems found in the general population. His dental morphology and anatomy are clinically the same as a "normal" patient's, and so may be his dental history, if it is one of neglect ending in acute dental decay or disease because he fears bleeding, pain, possible hospitalization, and loss of time from work or school.

Dental treatment for the hemophiliac is most effective as an integral part of a total rehabilitation program because the dental staff then has access to the physician, to the hospital, and to hematological and psychosocial services.

We feel that in order to establish safe outpatient care for the hemophiliac, the technique and conservative methods of dental treatment presented in this study need 
to be joined with the medical and psychological approaches and with patient education and cooperation. Dental procedures, especially extraction, should no longer be considered a life-threatening situation. The development of programs to treat hemophiliacs on either an outpatient or a private basis must be established. The financial burdens, time lost from work or school because of hospitalization, and the emotional and psychological problems with dental treatment warrant the development of such programs.

Observations of hemophilic patients by the investigator showed that a hemophilic patient postpones dental treatment partly because of his own ignorance of the need for dental care; partly because he fears ignorance on the part of dentists in the matter of treating hemophiliacs; and partly from discouragement about the prospect of still more loss of his time, continued disabilities, and perhaps hospitalization.

To summarize treatment, when the data were tabulated, 572 treatments and restorations were performed on 361 teeth in 107 hemophilic patients ranging in age from three to 57 years. Current work when tabulated will bring the totals to approximately 600 treatments on approximately 117 patients. From the research on these patients, the investigators have established safe restorative and surgical procedures for hemophiliacs.

\section{Acknowledgment}

Grateful acknowledgment is made to Osamu Miyamoto, D.D.S, for his assistance in the preparation of this paper and for his advice, which served to guide my research efforts over the three-year period which the project encompassed. Other members of the Hemophilia Project who demonstrated avid interest and cooperation in the clinical treatment of the hemophilic patients included: Shelby L. Dietrich, M.D., Medical Director of the Hemophilia Rehabilitation and Demonstration Project, Ronald S. Matsunaga, D.D.S., M.D., Thomas Mulkey, D.D.S., Larry Fukumoto, D.D.S., Roland Hansen, D.D.S., Ned Momary, D.D.S., Ernest Nagamatsu, D.D.S., Andon A. Andonian, M.D. and Shirley T. Whiteman, M.D.

\section{References}

[1] Abildgandd, C. F., Simone, J. V., Corrigan, J. J., Seeler, R. A., Edelstein, G., Vanderheiden, J., and SHULMAN, I.: Treatment of hemophilia with glycine-precipitated factor VIII, New Eng. J. Med., 275:471-475, Sept. 1, 1966.

[2] Alkjaersig, N., Fletcher, A. P., and Sjerry, F. L.: E-aminocaproic acid: An inhibitor of plasminogen activation, J. biol. Chem., 234(4):832-836, 1959.

[3] Andonian, A. A., Dietrick, S. L., and Whiteman, S. T.: I. Medical aspects in a total program for the patient with hemophilia, J. Amer. Phys. Therap. A., 46(11): 1269-1271, Nov. 1966.

[4] Archer, W. H.: Postextraction bleeding in a hemophiliac: Report of a case, J. oral Surg. oral Med., and oral Path., 4:849, July, 1951.

[5] Archer, W. H., and Zubrow, H. J.: Fatal hemorrhage following regional anesthesia for operative densittry in a hemophiliac, J. oral Surg., oral Med., and oral Path., 7:464-470, May 1954.

[6] Archer, W. H., and Zubrow, H. J.: Hemophiliac: The pre and post operative treatment: A case report, J. oral Surg., oral Med., and oral Path., 3:1377-1381, Nov. 1950. 
[7] Biggs, R., Rush, B. M., MacZarlane, R. G., Mathews, J. M., Johnstone, F. C., and HaytonWilliams, D. S.: Antihemophiliac globulin (H.A.H.G.) for the control of bleeding after dental extraction in hemophiliac patients: A Report to the Medical Research Council's Working Party on Human Anti-hemophiliac Globulin, Lancet, 1:969-975, May 8, 1965.

[8] Biggs, R., and MacFarlane, R. G.: Hemophilia and related conditions: A survey of 187 cases, Brit. J. Haemot, 4:1-27, Jan. 1958.

[9] Birch, C. L., and SnIDER, F. F.: Tooth extraction in hemophilia, J. Amer. d.Assn., 26:1933-1942, Dec. 1939.

[10] Bjordnal, A. M.: Endodontic treatment of an upper first molar in a hemophiliac, J. oral Surg., oral Med., and oral Path. 14:472-472, April 1961.

[11] Brinkhouse, K. M.: Anti-hemophiliac fractions from animal plasmas: Present status, Transfusion, 2(2): 85-87, March-April, 1962.

[12] Brinkhouse, K. M., and Graham, J. B.: Hemophilia and hemophiliod states, Bul. Union Co Dent. Soc., 39:4-7, Jan. 1960.

[13] Brinkhouse, K. M., and Graham, J. B.: Hemophilia in the female dog, Science, 3:723-724, 1950.

[14] Browne, W., Mally, M., and Kame, R. P.: Psychological aspect of hemophilia, Amer. J. Orthopsychiatry, 30(4):730-740, 1960.

[15] Bumsted, W. D., Glandon, C. J., and Roffinella, J. P.: Oral surgery in the hemophiliac-A Case report, South Calif. S. dent. A. J., 31:327-333, Sept.-Oct. 1955.

[16] Burtner, O. W.: Tooth extraction in hemophilia, J. Florida dent. Soc., 21:5-8, Sept. 1950.

[17] CASH, R. M.: Extraction of teeth for hemophiliacs, Australian dent. J., 46:232, Dec. 1942.

[18] Cazal, P.: Surgical intervention in hemophiliac patients, Anesthes., Berlin, 8:129-134, May 1959.

[19] Cohen, I.: Dental hemorrhage, J. oral Surg., oral Med., and oral Path., 2(7):704-706, July, 1958.

[20] Cunningham, J. J.: A case of hemophilia and its treatment, Dent. Cosmos, 76:1263-1265, 1934.

[21] Dalitsch, W. W.: Dental extractions, Hemophilia, J. Amer. dent. Assn., 21:1804-1811, Oct. 1934.

[22] Dietrich, S. L.: Personal communication: Medical Director, Project Hemophilia, Orthopaedic Hospital, 2400 South Flower Street, Los Angeles, Calif. 9007.

[23] Douglas, B. L.: Pseudohemophilia: Report of care, J. oral Surg., 16:77-79, Jan. 1958.

[24] Dunn, F. S.: Care and treatment of teeth of hemophiliac, J. Ontario dent. Assn., 37:13-14, April, 1960.

[25] Endicott, C. L., Mitchell, J. H., and Quist, G.: Asphyxia following dental extraction in a hemophiliac, Brit. med. J., p. 234, July 11, 1942.

[26] Findlay, I. A., and Nicholl, B.: Tooth extraction in patients with hemophilia, J. oral Surg., oral Med., and oral Path., 13:1167-1180, Oct. 1960.

[27] Finkelman, A.: Care of the hemophiliac patient in dental surgery, J. oral Surg., oral Med., and oral Path., 12:542-545, May, 1959.

[28] Fleuchaus, P. T.: Prolonged hemorrhage following extraction in a hemophiliac, J. oral Surg., oral Med., and oral Path., 7:720-725, July, 1954.

[29] Fonio, A.: Hemophilia, Dent. Abstr., 1:419, July, 1956.

[30] Gamble, J. W.: Fibrinogen advocated in hemophiliac surgery, Dental Times, p. 4, Nov. 15, 1964.

[31] George, W. A.: Prosthetic splints as an aid in the treatment of hemophilia, J.prosth. Dent., 11 :987-989, Sept.-Oct., 1961.

[32] Georgiade, N., Mitchell, T., and Lemler, J.: Use of a new improved hemostatic sponge in oral surgery, J. oral Surg., Anesth. and Hosp. Dent. Serv., 19:215-219, May, 1961.

[33] Gilbert, J. W., and Oldfield, H. M.: An improved method of constructing a splint for the control of hemorrhage, Dent. Prac. \& dent. Rec., 9:946-947, June, 1959.

[34] Gilchrist, G. S., Hammond, D., and Melnyk, J.: Hemophilia A in a phenotypically normal female with XX.XO Mosaicism, New Eng. J. Med., 273:1402-1406, Dec. 23, 1965. 
[35] Hartmann, J. R., and Bolduc, R. A.: Hemophilia, 1. Medical Care, 2. Nursing Care, Amer. J. Nursing, 52(2):169-172, Feb. 1956.

[36] Hattersley, P. G.: The treatment of classical hemophilia with cryoprecipitates, J. Amer. med. Assn. 198:243-244, Oct. 1966.

[37] Hayward, J. R.: Extractions in the hemophiliac, J. Mich. State dent. Assn., 47:209, July-Aug., 1965.

[38] Herbert, O.: Intraosseous infiltration of thrombin to arrest bleeding in cases of hemorrhagic diathesis including hemophilia, Internat. dent. J., 13:649, Dec. 1963 Yearb.

[39] Holland, D. J.: Hemophilia, including a detailed case report, Appollonian, 14:5, Oct., 1939.

[40] Hurt, C.: III. Psychosocial problems in a total program for the patient with hemophilia, $J$. Amer. Phys. Ther. A., 46(2):1282-1284, Nov. 1966.

[41] Ingram, G. I. C., and Winstock, D.: Oral surgical and prosthetic management of severe hemophilia, Proc. royal Soc. Med., 53:475, June, 1960.

[42] Israels, M. C. H., Lempert, H., and Gilbertsson, E.: Hemophilia in the female, Lancet, $1: 1375-$ 1380, June 30, 1951.

[43] Johnson, J. H.: More about bleeders, Oral Health, 51:385-388, June, 1961.

[44] Kaplan, R. E., Werther, R., Carson, I. H., and Wolman, I. J.: Dental care of the hemophiliac patient, Dent. Clinics of No. Am., W. B. Saunders Co., Philadelphia, p. 491-501, July, 1960.

[45] Katz, A., MacAfee, I., and Gody, F.: Social and vocational adaptation of the hemophiliac adult. (Study reproduced by the National Hemophilia Foundation, 25 West 39th St., New York, New York, 10018.)

[46] Kerr, C. B.: The Management of Haemophilia. Australian Medical Publishing Co., Seame Street, Glebe, New South Wales, 1963.

[47] LaGuerre, F., and Kutscher, A. H.: Hemophilia, gingival bleeding, J. Clin. Stomat. Conf., 2:34-35, May, 1961.

[48] Landbeck, G.: Hemophiliac patient at the dental office, Dent. Abstr., 6:142, March 1961.

[49] Leatherdale, R. A. L.: Anesthesis for dentallextraction in hemophiliac, Anesth, 13:27, 1958.

[50] Leatherdale, R. A. L.: Respiratory obstruction in hemophiliac patients, Brit. med. J., 1:13161320, April, 1960.

[51] Levine, P.: Dental management of hemophiliacs: Hemophilia and Hemophiloid Diseases Chapel Hill, Univ. of No. Carolina Press, pp. 210-216, 1957.

[52] LewIS, J. H.: Inheritance of hemophilia, reprint. The National Hemophilia Found., 25 W. 39th St., New York, New York 10018, 1(2):1-2.

[53] Linenbert, W. B., and Horpole, H. J.: Full mouth extractions in a hemophiliac patient, $J$. oral Surg., oral Med., and oral Path., 14:782-787, July, 1961.

[54] Linz, A. M.: The hemophiliac as a problem in oral surgery; A critical review of the literature, New York. J. Dent., 21(1):9-14, Jan., 1951.

[55] Lucas, O. N., Finkelman, A., and Tocantins, L. M.: Dental extractions in the hemophiliac: control of the emotional factors by hypnosis, Amer. J. clin. Hypnos., 7:301-307, April, 1965.

[56] Lucas, O. N., and Geisler, P. H.: Dental extraction in a haemophilia "A" Female. Brit. $J$. oral Surg., 2(3):179-183, March, 1965.

[57] Lucas, O. N., Finkelman, A., and Tocantins, L. M.: Management of tooth extractions in hemophiliacs by the combined use of hypnotic suggestion, protective splints and packing of socket, J. oral Surg., Anesth. and Hosp. Dent. Serv., 20:488, Nov., 1962.

[58] Lucas, O. N., and Tocantins, L. M.: Problems in hemostasis in hemophiliac patients undergoing dental extractions, Ann. N.Y. Acad. Sciences, 115:470-480, July, 1964.

[59] Lucas, O. N., Bowman, W. D., Finkelman, A., and Tocantins, L. M.: Removal of a giant, cell reparative granuloma from the mandible of a hemophiliac: Report of case, J. oral Surg., Anesth. and Hosp. Dent. Serv., 21:70-76, Jan. 1963.

[60] MacFarlane, R. O.: Haemophilia and other hemorrhagic states, Brit. Surg. Pract., 4:366-377, 1948.

[61] MacFARlan, R. O., and Biggs, R.: Observations on fibrinalysis, spontaneous activity associa(ed with surgical trauma, Etc., Lancet, 2:862-864, Dec. 14, 1946. 
[62] McIntyre, H., Nour-Eldin, F., Israels, M. C. G., and Wilkinson, J. F.: Dental extraction in patients with haemophilia and Christmas disease, Lancet, 7104:642-646, Oct. 24, 1959.

63] McIntyre, H.: Dental extractions in patients with hemophilia syndrome. J. oral Surg, oral Med., and oral Path., 19(2):163-174, Feb., 1965.

[64] Marder, V. J., Gamble, J. W., and Shulman, N. R.: The use of fraction I for oral surgical procedures in patients with classic hemophilia-Report of seven cases, J. oral Surg., 24:387499, Nov., 1966.

[65] Marlette, R. H., and Gerhard, R. C.: Reconstituted human fibrinogen in the treatment of hemophilia: Report of a case, J. oral Surg., oral Med., and oral Path., 17:691-695, May, 1964.

[66] Matheson, W. S.: dental extractions in cases of hemophilia, Brit. dent. J., 87:312-321, Dec. 1949.

[67] Matteson, A., and Gross, A.: Adaptational and defensive behavior in young hemophiliacs and their parents, A paper read at the 121st Ann. Mtg. of the Am. Psychiatric Assn., New York City, New York, May 3-7, 1965.

[68] Merskey, C.: Hemophilia occurring in the human female, proc., 3rd internat. soc. hemat., Cambridge, 1950, Grune and Stration, New York, 1951, pp. 441-446.

[69] Middleton, D. S., Davies, S. H., Cumming, R. A., Kamel, K., and Cameron, A.: Experience with thirty-six dental extractions in patients with hemophilia and Christmas disease, oral Surg., oral Med., and oral Path., 19:283-291, March, 1965.

[70] Myer, I.: Coagulation studies in hemophilioid diseases: their importance in treatment planning, J. oral Surg. Anesth., and Hosp. Dent. Serv., 22:324-331, July, 1964.

[71] Nathan, A. S., Rubin, B. J., and Rosen, M. B.: Conservative treatment of a large radicular cyst of the mandidle in a patient with severe hemophilia: Report of a Case, J. oral Surg., oral Med., and oral Path., 17:426-433, April, 1964.

[72] Neala, A. V.: Some relationships between blood disorders and dental diseases, Brit. dent. J., 54:600, 643-646, June, 9133.

[73] Nicholas, F. C., and Baldridge, O. L.: Multiple extractions for the hemophiliac, J. oral Surg., 12:31-42, Jan., 1954.

[74] OGden, I. W.: Hemophilia: establishment of diagnosis. Report of a case, J. oral Surg., oral Med., and oral Path., 8:1245-1249, Dec., 1955.

[75] OGston, D.: Influences of anxiety on coagulation, Lancet, 2:521-523, Sept. 15, 1962.

[76] Orr, J. A., and Douglas, A. S.: Tooth extraction in hemophiliac patients. Dent. Abstr., 2:684, Nov. 1957.

[77] Pavlovsky, A., and Pavlovsky, M. C.: Female hemophilia-Hemophilia and other hemorrhagic states. Internat. Symposium, Rome, The University of North Carolina Press, p. 69, Sept. 12, 1958.

[78] Pavlosky, A.: The marriage problem and descendants of hemophiliacs. Hemophilia and Hemophilioid diseases, K. M. Brinkhous, ed., Chapel Hill, University of North Carolina Press, 1957, pp. 163-166.

[79] Pinninger, J. L., and Franks, R. B.: Haemophilia in the female. Lancet, 2:82, July 14, 1951.

[80] PoInsard, P. P.: Psychiatric aspects of hemophilia. Proceedings, Institutes on Hemophilia. The National Hemophilia Foundation, 25 West 39th St., New York, New York 10018, June, 1965.

[81] Pool, J. G., and Shannon, A. E.: Production of high-potency concentrates of anti-hemophilic globulin in a closed-bag system. New Eng. J. Med., 273:1443-1447, Dec. 30, 1965.

[82] Quick, A. J., and Hussey, C. V.: Hemophilic conditions in a girl. Am. J. Dis. Child, 85:698 705, 1953.

[83] Quick, A. J., and Hussey, C. V.: Hemophilic conditions in the female, J. Lab. Clin. Med., 42: 929-930, 1953.

[84] QuICK, A. J.: Management of hemophilia in general practice. J. Amer. med. Assn., 145:4, Jan., 1951.

[85] Quick, A. J.: Sporadic hemophilia, Arch. Int. Med., 106:335-340, Sept., 1960.

[86] Reid, W. O., Lucas, O. N., Francisco, J., Geisler, P., and Ersley, A. J.: The use of epsilonaminocaproic acid in the management of dental extractions in the hemophiliac, Amer. J. med. Sc., 248(2):184-188, Aug., 1964. 
[87] Rosenthal, M. C.: Management of hemophilia: Current Therapy, W. B. Saunders Co., Philadelphia, 1959.

[88] Rubin, B., Levine, P., and Rosenthal, M. C.: Complete dental care of the hemophiliac, J. oral Surg., oral Med., and oral Path., 12:665-675, June, 1959.

[89] Sherry, J.: Treatment of the handicapped child, Clinical Pedodontic, W. B. Saunders Company, Philadelphia, 1958.

[90] Simmons, H. O., Jr.: Case history of hemophilia, J. Dent. Child., 23:235-240, 1956.

[91] Sjoerdsma, A., and Nilsson, I. M.: Aliphatic amino compounds as inhibitors of plasminogen Activation, Proc. Soc. Exp. Biol. and Med., 103:533-535, July, 1960.

[92] Stapp, W. F., Hayduk, J. W., Engleman, J. L., and Stout, R. A.: Control of secondary bleeding following tooth extraction in hemophilia, J. oral Therap. and Pharmacol., 2(4):275-284, Jan., 1966.

[93] TAYLOR, C.: IV. Educational-vocational aspects in a to talprogram for the patient with hemophilia. J. Amer. Phys. Therapy A., 46(11):1284-1285, Nov., 1966.

[94] TomeY, V. E.: Treatment of hemorrhage and hemophilia in dental practice, Brit. dent. J., 70: 325, May, 1941.

95] Trieger, N., and McGovern, J. J.: Evaluation of corticosteroid in hemophilia (A controlled study during oral surgery), New Eng. J. Med., 266:432-437, March 1, 1962.

[96] Trieger, N., and McGovern, J. J.: Hemophilia corticosteroids and oral surgery, J. dent. Res., 38:742-743, July-Aug., 1959.

[97] Trieger, N., and McGovern, J. J.: Plasma thromboplastin antecedent (PTA) Deficiency and oral surgery. J. oral Surg., oral Med., and oral Path., 10(1):55-62, Jan., 1957.

[98] Trieger, N., and McGovern, J. J.: Use of prednisone in hemophiliacs undergoing tooth extraction, Dent. Abstr., 7:464-465, Aug., 1962.

[99] VANDERHAMm, L. A.: Effective control of severe hemorrhage from the oral cavity (Tooth Sockets) to a probable true hemophiliac. Report of a case. Texas dent. J., 74:7, Jan., 1956.

[110] WaAler, B. A.: Diagnosis and treatment of hemophilia, Tskr. Norske Laegefor, 79:11111118.

[101] Webster, W. P.: Dental aspects of hemophilia, Proc., Inst. on Hemophilia sponsored by the Nat. Hemophilia Foundation, 25 West 39th St., New York, New York 10018, pp. 54-59, June 10-15, 1965.

[102] Webster, W., Robert, H. R., Thelin, G. M., Wagner, R. H., and Brinkhous, K. M.: Clinical use of a new glycine-practipitated antihemophilic franction, Amer. J. med. Sc., pp. 643-65, Dec., 1965.

[103] WheELer, G. E., and WAdlung, R. R.: The efficiency of fraction I. of normal human bood plasma in the extraction of the teeth in a hemophilic patient, J. Amer. dent. Assn., 38:273-274, Fleb. 1949.

[104] Whissell, D. Y., Hoag, M. S., Aggeler, P. M., Kropatkin, M., and Garner, E.: Hemophilia in a woman, Amer. J. Med., 38(1):119-129, Jan., 1965.

[105] White, P. H., and Mallett, S. P.: Management of hemophilia in dental extractions, Illinois dent. J., $18: 412-420$, Oct., 1949.

[106] White, D. W.: Home care of the hemophiliac child, Reprint, The Nat. Hemophiliac Foundation, 25 W. 39th St., New York, New York 10018, pp. 1-4.

[107] Wilson, C. J.: Dental care of hemophiliac. J. Wisc. dent. Assn., 41(5):167-169, May, 1965.

[108] Winstock, D., Ingram, G. I. C.: Dental extractions in hemophilia: Plasma therapy without dental splints., Dent. Abst., 6:614, Oct., 1961.

[109] Wishart, C., Annand-Smith, C., Honey, G. E., and Taylor, K. B.: Dental extraction in hemophilia, Lancet, 273:363-366, Aug., 1957.

[110] Sishart, C.: Oral surgery in hemorrhagic states, J. oral Surg., Anesth. and Hosp. Dent. Serv., 22:178-183, March, 1964. 